\title{
IoT Technology with Fuzzy Logic Control Integrated System to Achieve Comfort Environment
}

\author{
A Miqdad ${ }^{1}$, K Kadir ${ }^{2}$, Syed Faiz Ahmed ${ }^{3}, Z_{\text {Zuriati Janin }}^{4}$, Sheroz Khan $^{5}$ \\ ${ }^{1,2,3}$ Electrical Technology Section, Universiti Kuala Lumpur British Malaysian Institute (UniKL BMI)Malaysia \\ ${ }^{4}$ Faculty of Electrical Engineering, UniversitiTeknologi MARA (UiTM) Malaysia \\ ${ }^{5}$ Kulliyyah of Engineering, International Islamic University Malaysia (IIUM) Malaysia
}

Article History: Received: 10 November 2020; Revised: 12 January 2021; Accepted: 27January 2021; Published online: 05April 2021

\begin{abstract}
Internet of Thing technology is known for its capability to collect and store a massive amount of data for further research development. Researcher widely utilizes this technology as it has become a very convenient tool with a costeffective advantage. Practically, the calculation is made before determining the best cooling device for every room with temperature, humidity and power consumption being an important element to be taken into account. This paper present the practical approach to acquire data using WSN and IoT technology which then lead to the development of fuzzy logic control of the air conditioner with the aim to reduce its overall power consumption. Classroom equipped with two non-inverter airconditioners with 4HP each used as a testbed.
\end{abstract}

Keywords:Energy efficiency, IoT, WSN, Fuzzy Logic

\section{Introduction}

The concern on reducing energy consumption is vital not only to industries player but also to a household as it contributes to big saving on operational cost. Diversify climates and weather play a significant role in designing building structure, shape and its internal space. Cooling and heating load vary depending on the structure of a building, and its designated function [1,2] and indoor temperature [3] is directly affected by the outdoor environment change [4,5]. Well-known as the device that consumes high electricity to control temperature does not stop air-conditioner from being widely installed worldwide, especially in the Asia region [6]. This trend will be likely to continue as many studies suggest that high demand of air-conditioner will increase significantly in the near future as temperature specifically in dense cities area is expected to keep on rising $[7,8]$.

Nowadays, smart buildings seem to be the right answer for global concern on managing energy consumption usage as it comprises intelligent technologies to regulate the energy demand of the building autonomously. The capabilities to provide comfort surroundings at low power consumption lead to a reduction in environmental pollution among the advantage of smart building [9]. The technologies utilized include the Internet of Thing (IoT) and Artificial Intelligent (AI). Monitoring building activities using the sensor network are actively implemented in the research area [10-14]. Mainly, to acquire data heavily related to operational of Building Management System (BMS). Compare to regular operation, up to $40 \%$ of energy are expected can be saved on building operational cost by utilizing sensor networks system [15-19].

Currently, the ASHRAE standards and ISO7730 are used in designing the heating, ventilation and airconditioning (HVAC) system, which are based on the Predicted Mean Vote (PMV) model [20-23]. In this model, temperature setpoint is determined according to satisfaction by the majority. An alternative way of determining the comfort level of the building occupant is based on observation of human behaviour called 'adaptive approach'. This method acknowledges that occupants actively regulate thermal comfort by the opening window $[24,25]$, changing cloth [26-28], etc.

\section{Research Method}

Space involves in this experiment is classroom with 41.17-foot length, 21.82-foot width and 10.50 foot high. The classroom is designed to cater 61 occupants at a time, as shown in Figure 1. Air-conditioner sizing is imperative in order to control the ambient temperature of any given space successfully. They are calculating the accurate capacity required on-site valuation since several factors need to be taken into consideration. BTU's (British Thermal Units) is used to measure the power of air-conditioner. Conversion from BTU's into Kw is given by:BTU x $0.0002928=\mathrm{kW}$ 




Figure 1.Space cooling of classroom

Figure 2 illustrates the connection made to obtain real-time data of power consumed by the air-conditioner. The system structure requires measurement of power consumption to be taken atthe electrical panel at the riser room. Two current transformers then were clamped at the outgoing cable from separate circuit breaker for both devices. A microcontroller is applied to link all the current transformer outgoing data to the cloud server. The real-time data then is processed and monitored using a computer.

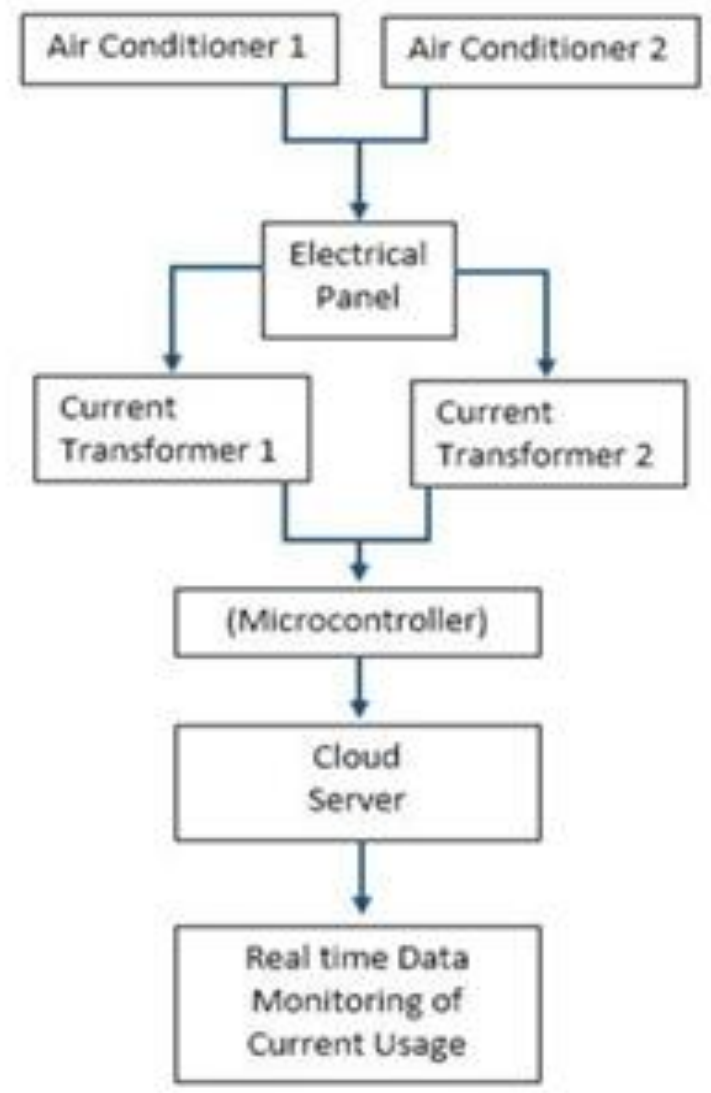

Figure 2.Network architecture

\section{Results and Analysis}

The type of air conditioner utilized in the experiment have single speed compressor and single tonnage. Figure 3 is the effect of changes in air-conditioner set to the ambient temperature and humidity of the room. 


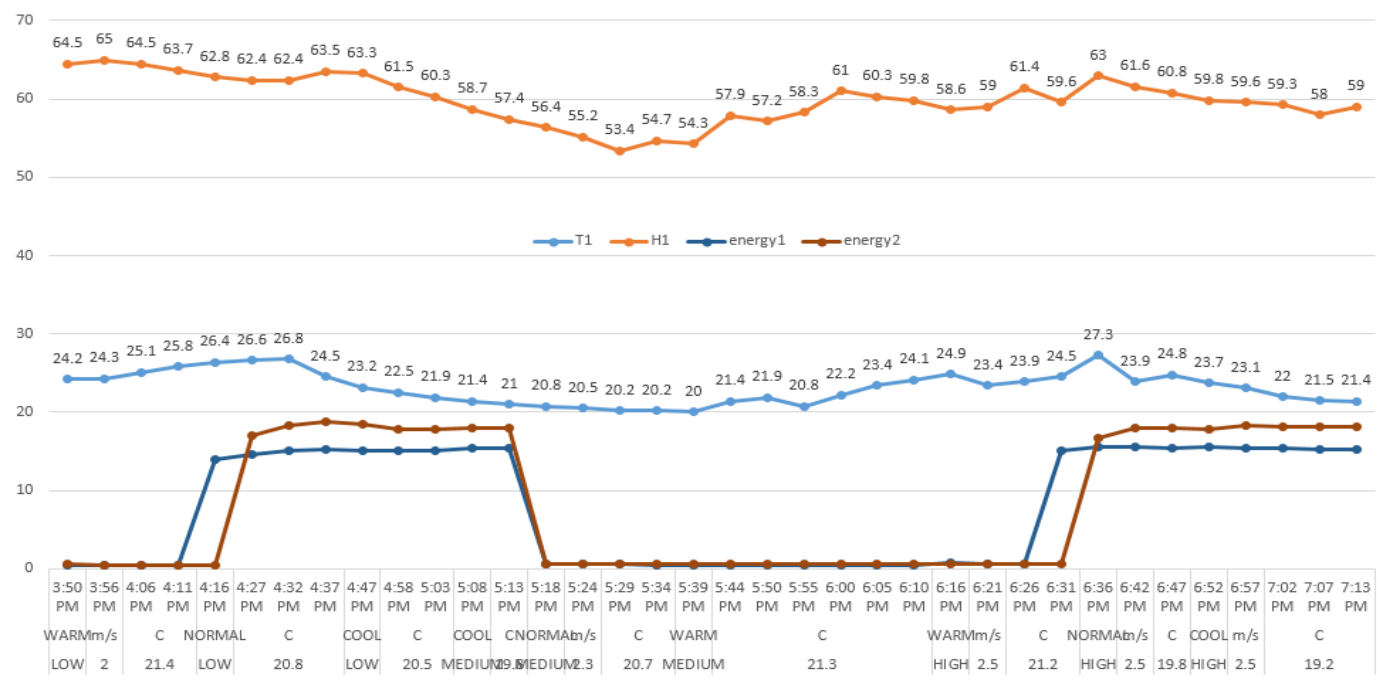

Figure 3.Effects of selecting different switching under dynamic condition

The setting was changed to nine different arrangement with a combination of fan speed and temperature. The graph demonstrates a substantial differencein energy consumption between the cold and warm setting of temperature. Throughout the experiment, the lowest reading is $20^{\circ} \mathrm{C}$ with $54.3 \%$ humidity, and the highest recorded temperature is $27.3^{\circ} \mathrm{C}$ at $63 \%$ humidity with initial ambient temperature measured at $24.2^{\circ} \mathrm{C}$ with $64.5 \%$ humidity. The lowest reading of temperature obtained at minimum used of electrical energy after the air conditioner has worked at high capacity to cool down the temperature during the start of the experiment.

\subsection{Overall Tabulated Data}

Table 1.Average Wind Speed in $\mathrm{m} / \mathrm{s}$

\begin{tabular}{|l|l|l|l|}
\hline Air Temp /Fan & Low & Medium & High \\
\hline Warm & 2.0 & 2.3 & 2.5 \\
\hline Normal & 2.0 & 2.3 & 2.5 \\
\hline Cool & 2.0 & 2.3 & 2.5 \\
\hline
\end{tabular}

Table 2. Average Cool Air Temperature in ${ }^{\circ} \mathrm{C}$

\begin{tabular}{|l|l|l|l|}
\hline Air Temp /Fan & Low & Medium & High \\
\hline Warm & 21.4 & 21.3 & 21.2 \\
\hline Normal & 20.8 & 20.7 & 19.8 \\
\hline Cool & 20.5 & 19.8 & 19.2 \\
\hline
\end{tabular}

Table 3. Average Current Flow in Ampere (A)

\begin{tabular}{|l|l|l|l|}
\hline Air Temp /Fan & Low & Medium & High \\
\hline Warm & 0.5 & 0.6 & 0.7 \\
\hline Normal & 16.5 & 16.8 & 17.0 \\
\hline Cool & 17.8 & 18.0 & 18.3 \\
\hline
\end{tabular}

The average reading of wind speed and initial air temperature blowing out from the air-conditioner shown in Table 1 and Table 2. Shifting fan speed from low to medium giving percentage different of $13 \%$ and $8 \%$ from medium to high while the temperature of initial cool air ranging from $21.4^{\circ} \mathrm{C}$ to $19.2^{\circ} \mathrm{C}$. Table 3 show the amount of current flowing to the air-conditioner for each different setting. The air-conditioner consumes significantly lesser energy when the temperature is set to warm regardless of the fan speed.

\subsection{Fuzzy Logic Control}


ASHRAE Standard 55-2013 state that comfort temperature can range from $19^{\circ} \mathrm{C}$ to $28^{\circ} \mathrm{C}$ and ASHRAE Standard 62.1-2016 mention relative humidity should be less than $65 \%$ to avoid a moist environment that can lead to microbial growth. Many factors such as season, clothing is worn, and activity levels need to be put under consideration before determining appropriate range for comfort environment.

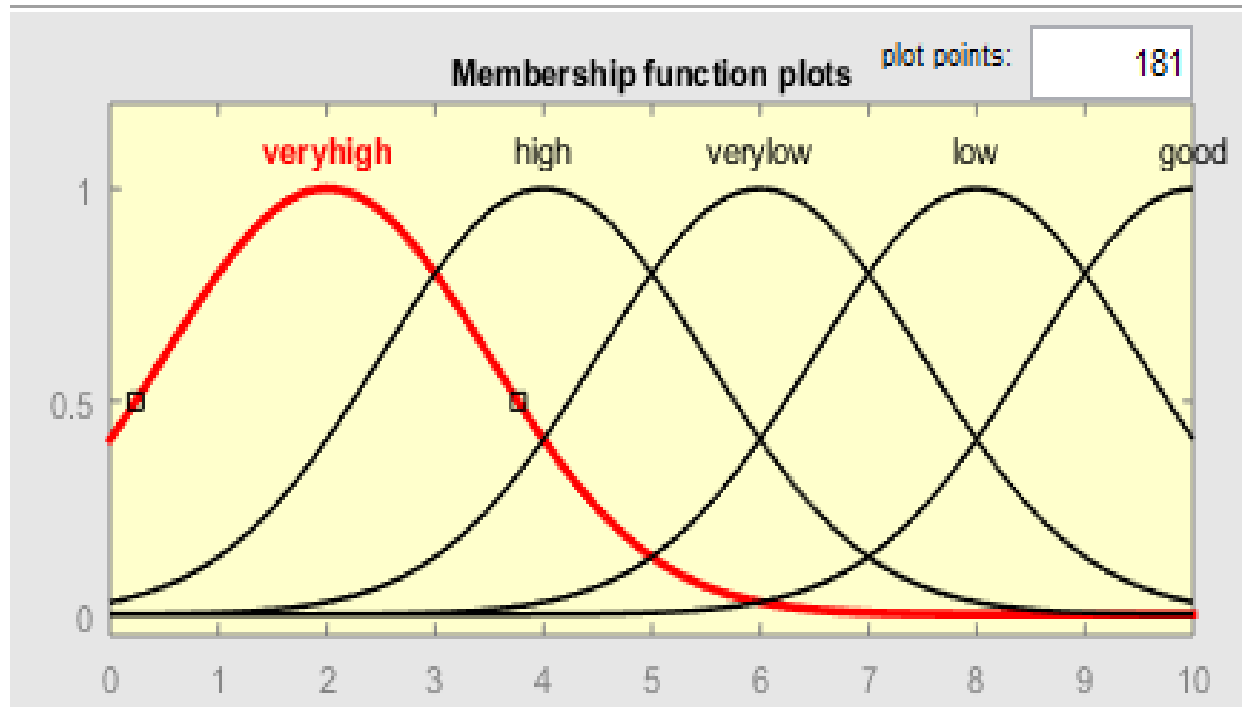

Figure 4.Input variable for temperature and humidity

Figure 4 shows the index of comfort level tabulated in the scale of one to ten with ten being the most comfortable and preferred environment. Base on normal environment condition, comfortable room temperature should be at $23^{\circ} \mathrm{C}$ with $45 \%$ humidity. Very high humidity is set to be above $60 \%$, humidity in the range of $45 \%$ to $59 \%$ is considered high, $31 \%$ to $44 \%$ is set to low while less than $30 \%$ is very low and the most preferred humidity is set at $45 \%$. Temperature above $26^{\circ} \mathrm{C}$ is set to be in very high and $24^{\circ} \mathrm{C}$ to $25^{\circ} \mathrm{C}$ is put under the high zone. The temperature in the range of $20^{\circ} \mathrm{C}$ to $22^{\circ} \mathrm{C}$ is low, less than $19^{\circ} \mathrm{C}$ is very low, and the preferred temperature is set at $23^{\circ} \mathrm{C}$.

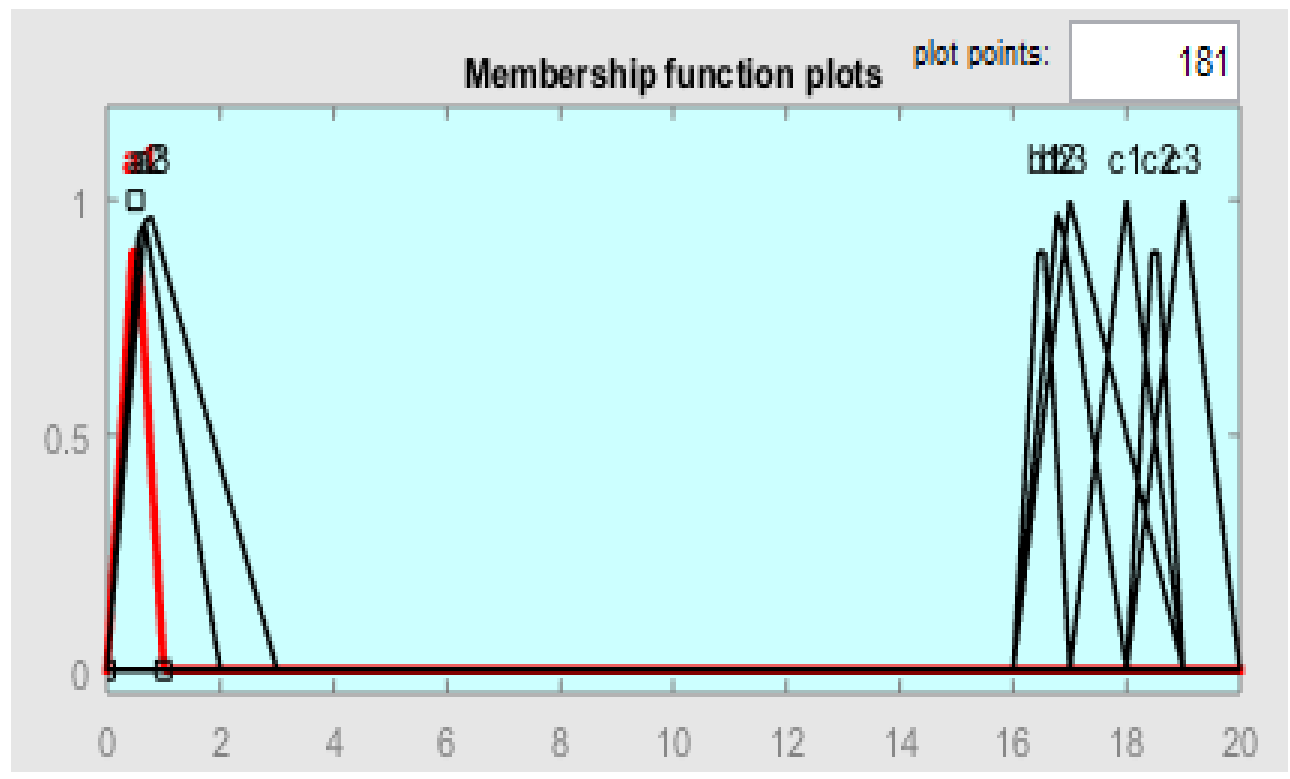

Figure 5.Output variable for current (ampere)

Nine membership function represent the different outcome of current accordingly. Based on Figure 5, the current usage surge to almost peak at average 17A when the temperature setting change to normal or cool while only $0.55 \mathrm{~A}$ is used when the temperature is set to warm. This huge gap in power usage between settings exhibit the disadvantage of the cooling device involves in this experiment. 


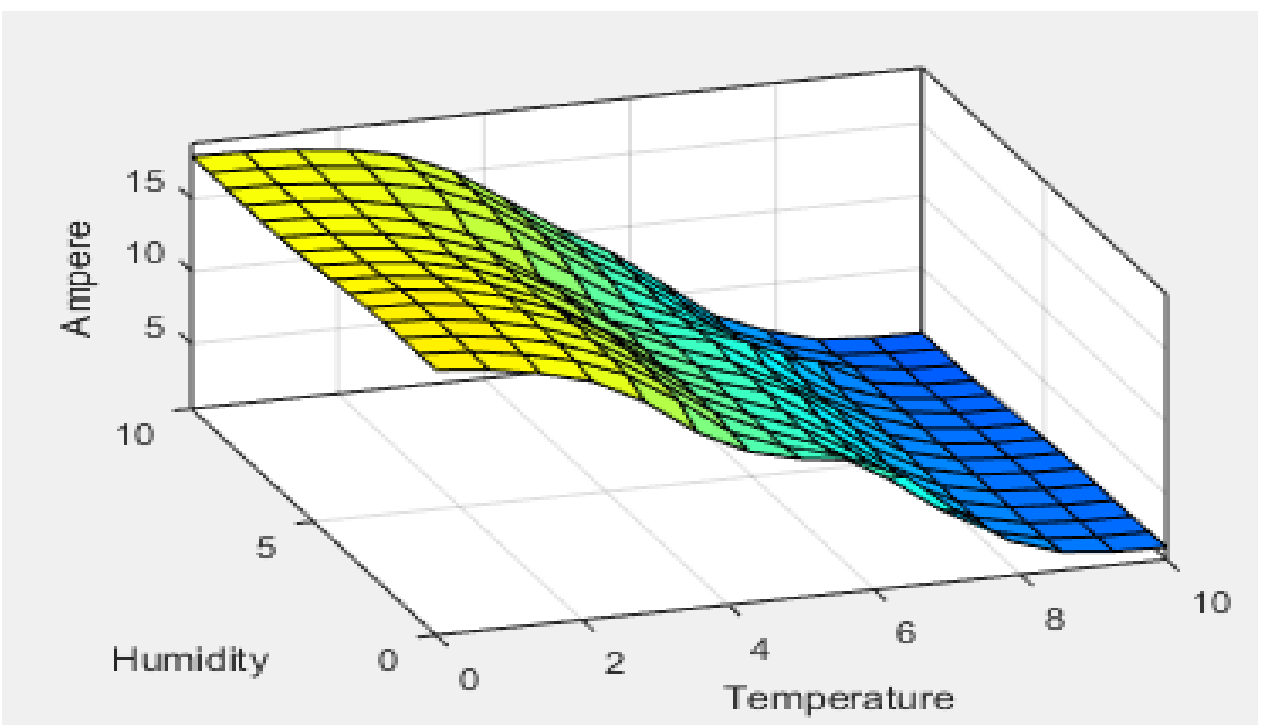

Figure 6.Output variable for current (ampere)

Surface view of fuzzy logic control shown in Figure 6 demonstrates a smooth operational current flow into the cooling device to maintain comfort environment. Power consumption reduces as ambient temperature, and humidity condition improves towards the best comfort parameter set at 10. Fuzzy logic control allows enhancement of energy efficiency to take place even though the compressor of an air-conditioner is not set for variable speed and tonnage.

\section{Conclusion}

This paper reveals the exact power consumption reading of non-inverter air-conditioner and demonstrate the benefit of fuzzy logic control to improve its energy efficiency. Utilizing WSN and IoT technology to record and store a massive amount of data has been tremendously helpful in attaining desire result. As the most significant power-consuming device, air-conditioner role in delivering comfort environment for building occupant need to be continuously improved from time to time. Without denying the importance of carrying out preventive maintenance of air-conditioner, there many ways that can be implemented to save cash on the electricity bill. Replacing the old existing traditional air-conditioner with newly better energy efficient inverter technology airconditioner is very costly. Hence, the advantage of artificial technology (AI) and control system must be explored to tackle high energy usage issue and to assist in reducing operational cost.

\section{Acknowledgements}

The author would like to thank the UniversitiTeknologi MARA and Universiti Kuala Lumpur British Malaysian Institute for supporting this research work.

\section{References}

1. Pita, Edward G., "Air Conditioning Principles and Systems 4th Edition," McGraw-Hill, 2002.

2. KJ Kontoleon, EA Eumorfopoulou, "The effect of the orientation and proportion of a plant-covered wall layer on the thermal performance of a building zone"building and environment, 2010 Elsevier, Vol 45

3. A Pasupathy, R Velraj, RV Seeniraj "Phase change material-based building architecture for thermal management in residential and commercial establishments"Renewable and Sustainable Energy, 2008 Elsevier, Vol 12

4. SM Sheweka, NM Mohamed "Green Facades As A New Sustainable Approach Towards Climate Change" Energy Procedia, 2012 Elsevier, Vol 18

5. L Klein, J Kwak, G Kavulya, F Jazizadeh "Coordinating Occupant Behavior For Building Energy And Comfort Management Using Multi-Agent Systems" Automation in Construction, 2012 Elsevier, Vol 22

6. T. Wang, et al., " A Fair and Budget-Balanced Incentive Mechanism for Energy Management in Buildings," IEEE Trans. Smart Grid,2010.

7. TA Nguyen, M Aiello "Energy intelligent buildings based on user activity: A survey"Energy and buildings, 2013 Elsevier,Vol 56 
8. CY Chong, SP Kumar "Sensor networks: evolution, opportunities, and challenges" Proceedings of the IEEE, 2003, ieeexplore.ieee.org, Vol 91

9. T Arampatzis, J Lygeros "A survey of applications of wireless sensors and wireless sensor networks" Proceedings of the IEEE 2005, ieeexplore.ieee.org

10. K Romer, F Mattern "The design space of wireless sensor networks" IEEE wireless communications, 2004, ieeexplore.ieee.org, Vol 11

11. Lam T, et al., "Impact Of Climate Change Oncommercial Sector Air Conditioning Energy Consumption In Subtropical Hong Kong," 2010 Elservier, Vols 872321-7, 2010.

12. MA Piette, SK Kinney, $P$ Haves "Analysis Of An Information Monitoring And Diagnostic System To Improve Building Operations" Energy and Buildings, 2001 Elsevier, Vol 33

13. P Siano "Demand response and smart grids-A survey"Renewable And Sustainable Energy Reviews 2014, Elsevier Vol 30

14. IF Akyildiz, W Su, Y Sankarasubramaniam, E Cayirci "Wireless sensor networks: a survey"Computer networks, 2002, Elsevier, Vol 38

15. PM Ferreira, AE Ruano, S Silva, EZE Conceicao "Neural networks based predictive control for thermal comfort and energy savings in public buildings"energy and buildings, 2012, Elsevier, Vol 55

16. Yun GY and Steemers K, "Behavioural, physical and socio-economic factors in household cooling energy consumption," in Applied Energy, 2011Vols 88 2191-200,2011.

17. Z. Wang, et al., "Customer-centered Control System for Intelligent and Green Building with Heuristic Optimization," 2011 IEEE Power System Conference and Exposition,2011.

18. Miqdad, et al.,"Space Cooling Load Monitoring System With IoT," ICSIMA, 2019

19. Spinar, et al., "Wireless Sensor Network Deployment for Building Environmental Monitoring and Control," 2011 Vols 70 Ambient Media and Systems 2011.

20. American Society of Heating, Refrigerating and Air-Conditioning Ashrae 55. 2004.

21. Fanger, "Thermal Comfort : Analysis and applications in environmental engineering" Danish Technical Press, 1970.

22. Ghahramani, et al.," A Human-Building Interaction Framework for Personalized Thermal Comfort Driven Systems in Office Buildings" Journal of Computing in Civil Engineering, 2013.

23. International Organization for Standardization Iso 7730. 2005.

24. J. F. Nicol. a. M. A. Humphreys, "Thermal Comfort as Part of a Self-regulating System," Building Research and Practice, vol. 1, no. 3, 1973.

25. J. F. Nicol. a. M. A. Humphreys, "Adaptive thermal comfort and sustainable thermal standards for buildings,"Energy and Buildings, vol. 34, no. 6, pp. 563-572, 2002.

26. J. F. Nicol. a. M. A. Humphreys, ""New standards for comfort and energy use in buildings," vol. 37, no. $1,2009$.

27. Gunawan, T. S., Yaldi, I. R. H., Kartiwi, M., \& Mansor, H. (2018). Performance evaluation of smart home system using internet of things. International Journal of Electrical and Computer Engineering, $8(1), 400$.

28. Ismail, N., Nursalim, I., Saputra, H. M., \& Gunawan, T. S. (2018). Implementation of fuzzy logic control system on rotary car parking system prototype. Indonesian Journal of Electrical Engineering and Computer Science (IJEECS), 12(2), 706-715. 